\title{
Genetic analysis of genes involved in dipeptide metabolism and cytotoxicity in Pseudomonas aeruginosa PAO1
}

\author{
Patrick D. Kiely, Julie O'Callaghan, Abdelhamid Abbas and Fergal O'Gara \\ BIOMERIT Research Centre, Department of Microbiology, University College Cork, Ireland
}

\begin{abstract}
Correspondence
Fergal O'Gara

f.ogara@ucc.ie
\end{abstract}

Received 13 November 2007

Revised 2 April 2008

Accepted 11 April 2008

\begin{abstract}
The dipeptide transport operon in bacteria comprises genes for the transport and metabolism of amino acids and dipeptides, as well as haem and haem precursors such as aminolaevulinic acid. Such nutrient and mineral sources are vital for bacteria to survive in and colonize a range of niches. In silico analysis of the dipeptide transport systems in sequenced Pseudomonas species identified the presence of two genes in $P$. aeruginosa strains that were absent in other sequenced pseudomonads. These genes encode a putative metallopeptidase, PA4498, and a putative transcriptional regulator, PA4499. Proteomic profiling of wild-type PAO1 and a PA4499 mutant strain indicated that PA4499 negatively regulated the putative peptidase, PA4498.

Transcriptional fusion analysis verified that expression of PA4498 ( $m d p A$, metallo-dipeptidase aeruginosa) was negatively regulated by the downstream putative transcriptional regulator PA4499 (psdR, Pseudomonas dipeptide regulator). Transcriptional fusion analysis also showed that the $d p p A B C D F$ operon was under the negative control of $p s d R$. Functional genomic analysis of $m d p A$ indicated that it is required for the metabolism of a range of dipeptides and that it contributes to the cytotoxicity of PAO1 on an epithelial cell line.
\end{abstract}

\section{INTRODUCTION}

Pseudomonas aeruginosa is a Gram-negative bacterium commonly isolated from soil and water and is renowned for its nutritional and ecological versatility. The ability to transport and metabolize an array of nutrients enables this bacterium to colonize a wide variety of niches. As an opportunistic human pathogen, $P$. aeruginosa is a common cause of nosocomial infections. It is responsible for persistent infection of immunocompromised individuals and can cause chronic lung infections in patients with cystic fibrosis (Govan \& Deretic, 1996). Given that epithelial cells act as the initial barrier to infection, an understanding of the interactions between these cells and the bacterium is critical. P. aeruginosa has also been shown to cause infections in non-mammalian hosts such as insects (Jander et al., 2000) and plants (Rahme et al., 1995; SiloSuh et al., 2002; Walker et al., 2004). The metabolic versatility of this bacterium is reflected in the fact that $10 \%$ of its genome encodes membrane-associated transporters, with a further $8 \%$ involved in the metabolism of carboncontaining compounds (Stover et al., 2000). One transport system of particular interest is the dipeptide $(d p p)$ transport operon because of its involvement in the transport of not only dipeptide containing compounds

Abbreviations: HTH, helix-turn-helix; LES, Liverpool epidemic strain; $\mathrm{XRE}$, xenobiotic response element. but also aminolaevulinic acid (Carter et al., 2002; King \& O'Brian, 1997), haem (Letoffe et al., 2006) and single amino acids (Tamber \& Hancock, 2006).

The $d p p$ transport operon has been well characterized and shows conservation in structure across both Gram-negative (Abouhamad \& Manson, 1994) and Gram-positive (Guedon et al., 2001; Slack et al., 1995) bacterial species. The $d p p$ operon has been shown to be maximally expressed in the stationary phase of growth, with expression driven from the promoter region upstream of the first gene, $d p p A$ (Abouhamad \& Manson, 1994). In Salmonella typhimurium and Escherichia coli, $d p p A$ has been shown to play a role in chemotaxis (Abouhamad et al., 1991). The role of the $d p p$ transport machinery in utilizing haem iron has also been shown in E. coli. Binding of haem by the DppA protein allows transport of this molecule into the cell via the $d p p B C D F$ ATP-binding cassette transporter (Letoffe et al., 2006).

To date relatively little information is available regarding the regulation of this transport machinery. Regulation of the $d p p$ transport operon in Bacillus subtilis has been shown to be exerted by the pleiotropic negative regulators CodY and AbrB (Slack et al., 1995). In Lactococcus lactis, a homologue of CodY was shown to respond to the levels of branched-chain amino acids, thereby sensing aspects of the nutritional supply for the cell. Additionally an $\operatorname{lrp}$ (encoding a leucine-responsive regulatory protein) gene 
from Bradyrhizobium japonicum has been shown to complement an $E$. coli $d p p$ mutant strain for the uptake of dipeptides (King \& O'Brian, 1997). In E. coli the $g c v B$ gene, which encodes a small untranslated RNA, has been shown to regulate expression of both the Dpp and oligopeptide (Opp) transport systems. This small untranslated RNA appears to regulate genes associated with oligopeptide transport at the translational level whereas it appears to regulate $d p p A$ expression at the mRNA level (Urbanowski et al., 2000).

$P$. aeruginosa $\mathrm{PAO} 1$ contains a gene cluster which shows a high level of homology to previously characterized $d p p$ transport operons (http://www.pseudomonas.com). Interestingly, transcriptome analysis has shown that $d p p A 3$ in $P$. aeruginosa $\mathrm{PAO}$ is induced under low-iron conditions (Ochsner et al., 2002). The porin OpdP, which is associated with this putative dipeptide transport machinery in $P$. aeruginosa $\mathrm{PAO1}$, is required for the transport of the dipeptide glycyl-glutamic acid (Tamber \& Hancock, 2006). The $o p d P$ gene is induced to a high level when bacteria are grown on the amino acid L-arginine, suggesting involvement of OpdP in the uptake of single amino acids as well as dipeptides (Tamber \& Hancock, 2006).

Previous transcriptome analysis of $P$. aeruginosa, carried out in the presence of a human airway epithelial cell line, showed that expression of the gene PA4498, encoding a putative metallopeptidase, was upregulated 4.8 -fold (Frisk et al., 2004). Variations in gene expression have been shown to influence the virulence of the Liverpool epidemic strain (LES) of $P$. aeruginosa. The highly virulent, epidemic strain LES431 has shown increased resistance to antimicrobials and has caused mortality in both immunocompromised and non-immunocompromised patients. Transcriptome analysis of this strain has shown that it also overexpresses the $m d p A$ gene, encoding a putative metallopeptidase (Salunkhe et al., 2005).

This paper identifies the $p s d R$ gene as a transcriptional repressor of the $m d p A$ and $d p p A 3$ genes. It also demonstrates that the $m d p A$ gene is essential for the growth of $P$. aeruginosa on dipeptides as sole carbon source and suggests an involvement of this gene in $P$. aeruginosa cytotoxicity.

\section{METHODS}

Bacterial strains, plasmids and growth conditions. Strains and plasmids used in this study are listed in Table 1. All cultures of $P$. aeruginosa $\mathrm{PAO} 1$ and associated mutants were routinely grown on Casamino Acid (CAA) medium supplemented with $100 \mu \mathrm{M} \mathrm{FeCl}_{3}, \mathrm{LB}$ or M9 minimal medium (Sambrook et al., 1989) at $37^{\circ} \mathrm{C}$. The mPA4498 (mPAmdpA) mutant strain was obtained from the University of Washington Mutant Library (Jacobs et al., 2003).

Table 1. Bacterial strains and plasmids used in this study

\begin{tabular}{|c|c|c|}
\hline Strain or plasmid & Description & Reference or source \\
\hline \multicolumn{3}{|l|}{ Pseudomonas aeruginosa } \\
\hline PAO1 & Wild-type & Holloway \& Morgan (1986) \\
\hline $\mathrm{PApsdR}$ & $\Delta p s d R:: \mathrm{Gm}^{\mathrm{r}}$ & This study \\
\hline $\mathrm{PAO} 1 / \mathrm{pMP} 220:: \mathrm{P} p s d R$ & $\mathrm{P} p s d R ;$ lacZ; $\mathrm{Tc}^{\mathrm{r}} \mathrm{Km}^{\mathrm{r}}$ & This study \\
\hline $\mathrm{PAO} 1 / \mathrm{pMP} 220:: \mathrm{P} d p p A$ & $\mathrm{P} d p p ;$ lacZ; $\mathrm{Tc}^{\mathrm{r}} \mathrm{Km}^{\mathrm{r}}$ & This study \\
\hline $\mathrm{PA} p s d R / \mathrm{pMP} 220:: \mathrm{P} d p p A$ & $\Delta p s d R:: \mathrm{Gm}^{\mathrm{r}} ; \mathrm{P} d p p A ; l a c Z ; \mathrm{Tc}^{\mathrm{r}} \mathrm{Km}^{\mathrm{r}}$ & This study \\
\hline $\mathrm{PA} p s d R / \mathrm{pMP} 220:: \mathrm{P} d p p A \mathrm{pBBR} p s d R$ & $\Delta p s d R:: \mathrm{Gm}^{\mathrm{r}} ; \mathrm{P} d p p A ;$ lacZ; $\mathrm{Tc}^{\mathrm{r}} \mathrm{Km}^{\mathrm{r}}: p s d R ; \mathrm{Cm}^{\mathrm{r}}$ & This study \\
\hline $\mathrm{PAO} 1 / \mathrm{pMP} 220:: \mathrm{P} m d p A$ & $\mathrm{P} m d p A ; l a c Z ; \mathrm{Tc}^{\mathrm{r}} \mathrm{Km}^{\mathrm{r}}$ & This study \\
\hline $\mathrm{PA} p s d R / \mathrm{pMP} 220:: \mathrm{P} m d p A$ & $\Delta p s d R:: \mathrm{Gm}^{\mathrm{r}} ; \mathrm{P} m d p A ; l a c Z ; \mathrm{Tc}^{\mathrm{r}} \mathrm{Km}^{\mathrm{r}}$ & This study \\
\hline $\mathrm{PA} p s d R / \mathrm{pMP} 220:: \mathrm{P} m d p A$ pBBR $p s d R$ & $\Delta p s d R:: \mathrm{Gm}^{\mathrm{r}} ; \mathrm{P} d p p A ;$ lacZ; $\mathrm{Tc}^{\mathrm{r}} \mathrm{Km}^{\mathrm{r}}: p s d R ; \mathrm{Cm}^{\mathrm{r}}$ & This study \\
\hline mPAO1 & Wild-type & Jacobs et al. (2003) \\
\hline $\mathrm{mPA} m d p A$ & $m d p A:: \operatorname{Tn} 5 \mathrm{Tc}^{\mathrm{r}}$ & Jacobs et al. (2003) \\
\hline \multicolumn{3}{|l|}{ Escherichia coli } \\
\hline TOP $10 \mathrm{~F}^{\prime} \mathrm{DH} 5 \alpha$ & TOPO chemically competent cells & Invitrogen \\
\hline XL1 Blue & Chemically competent cells & NEBioLabs \\
\hline \multicolumn{3}{|l|}{ Plasmids } \\
\hline pBBR1MCS & Cloning vector, $\mathrm{BHR}, \mathrm{Cm}^{\mathrm{r}}$ & Kovach et al. (1994) \\
\hline TOPO Z & TOPO cloning vector & Invitrogen \\
\hline pMP220 & Transcriptional reporter & Spaink et al. (1987) \\
\hline $\mathrm{P} \Delta p d s R 1$ & TOPO-Frg1-Gen-Frg2, $p s d R::$ Gen & This study \\
\hline $\mathrm{p} K 19 \Delta p s d R$ & pK19-Frg1-Gen-Frg2, $p s d R::$ Gen & This study \\
\hline pTF99 & $\mathrm{P} p s d R: l a c Z$ pmp220 & This study \\
\hline pTF98 & PmdpA:lacZ pmp220 & This study \\
\hline pTF00 & $\mathrm{P} d p p A: l a c Z$ pmp220 & This study \\
\hline pRK2013 & Helper plasmid, $\mathrm{Tra}^{+} \mathrm{Mob}^{+}$ColE1 $\mathrm{Km}^{\mathrm{r}}$ & Figurski \& Helinski (1979) \\
\hline pK19mobsac & Suicide vector & Schafer et al. (1994) \\
\hline
\end{tabular}


E. coli strains were routinely grown in LB medium at $37{ }^{\circ} \mathrm{C}$. Where appropriate, antibiotics were added to growth media at the following concentrations: for $P$. aeruginosa, $50 \mu \mathrm{g}$ kanamycin $\mathrm{ml}^{-1}, 200 \mu \mathrm{g}$ chloramphenicol $\mathrm{ml}^{-1}$ and $50 \mu \mathrm{g}$ gentamicin $\mathrm{ml}^{-1}$; for E. coli, $25 \mu \mathrm{g}$ gentamicin $\mathrm{ml}^{-1}, 50 \mu \mathrm{g}$ ampicillin $\mathrm{ml}^{-1}$ and $12.5 \mu \mathrm{g}$ tetracycline $\mathrm{ml}^{-1}$.

Mammalian cell culture. Immortalized human epithelial cell line 16HBE140 S-1 was obtained from P. B. Davis (Case Western Reserve University) (Kube et al., 2001; Rajan et al., 2000). Cells were cultured on BSA-collagen-fibronectin-coated plastic, using minimum essential medium supplemented with $10 \%$ fetal bovine serum, $2 \mathrm{mM} \mathrm{L-}$ glutamine, $100 \mu \mathrm{g}$ penicillin $\mathrm{ml}^{-1}, 100 \mu \mathrm{g}$ streptomycin $\mathrm{ml}^{-1}$ and $400 \mu \mathrm{g}$ neomycin G-418 $\mathrm{ml}^{-1}$. Cells were incubated at $37{ }^{\circ} \mathrm{C}$ in a humidified $5 \% \mathrm{CO}_{2}$ atmosphere. All cell culture reagents were supplied by Sigma, unless stated otherwise.

DNA and RNA manipulations. Restriction digests, ligations, transformations and agarose gel electrophoresis were performed as described by Sambrook et al. (1989). All restriction enzymes were obtained from Roche Pharmaceuticals. Small-scale plasmid DNA isolation was performed using the Qiagen Plasmid Mini-kit according to the manufacturer's instructions. Prior to cloning, PCR products were purified either from agarose gels using the Qiagen Gel Extraction kit or directly from solution using the Qiagen PCR Purification kit and cloned into the pCR2.1TOPO plasmid using the TA cloning kit according to the manufacturer's specifications (Invitrogen). Plasmids were mobilized into Pseudomonas strains by triparental mating using the helper plasmid pRK2013 (Figurski \& Helinski, 1979).

Determination of nucleotide sequence and sequence analysis. All transcriptional fusions and $p s d R$ gene disruption were confirmed by nucleotide sequencing performed at Lark Technologies. The sequence data were assembled using the DNASTAR software package and analysed using the University of Wisconsin genetic computer group (GCG) program FASTA (Pearson \& Lipman, 1988) and BLAST (Altschul et al., 1990) at the National Centre for Biotechnology Information (NCBI). Multiple sequence alignments were performed using the CLUSTAL W program (Chenna et al., 2003).

Construction of the psdR mutant. To construct a $P A 4499(p s d R)$ negative mutant we first amplified two genomic fragments. Fragment 1 (Frg1) covers the region extending from +1435 to -130 relative to the PA4498 ( mpdA) ATG start codon, and fragment 2 (Frg2) covers the region extending from +270 relative to the $p s d R$ ATG start codon to +507 relative to the $P A 4500(d p p A 3)$ ATG start codon. These two fragments are located 348 bp apart. The joining of Frg1 and Fgr2 would delete $348 \mathrm{bp}$ of the $p s d R$ gene including $58 \mathrm{bp}$ of the untranslated region upstream to the ATG and the first 96 codons of the $p s d R$ ORF. We engineered PstI and NotI restriction sites at the $5^{\prime}$ and the $3^{\prime}$ ends of Frg1 and NotI and XbaI restriction sites at the 5' and the $3^{\prime}$ ends of Frg2 respectively. These fragments were separately cloned into the TOPO cloning vector. Frg1 and Fgr2 were then joined at the NotI site. The vector containing Frg1 and Frg2 was linearized at the NotI site and ligated to the gentamicin-resistance cassette digested with the same restriction enzyme to produce the recombinant plasmid $\mathrm{P} \Delta p s d R 1$ containing a disrupted $p s d R$ gene. The disrupted gene was transferred to into the allelic-exchange vector pK19mobsac using PstI and XbaI restriction sites to create $\mathrm{p} K 19 \Delta p s d R$. The $s a c B$ gene contained on pK19mobsac codes for the enzyme levansucrase, which confers sucrose susceptibility to cells expressing the intact gene. Triparental mating was carried out to transfer this construct from $E$. coli XL1 to $P$. aeruginosa PAO1 wild-type strain. The positive clones, which had integrated the plasmid into the chromosome, were selected for on $50 \mu \mathrm{g}$ gentamicin $\mathrm{ml}^{-1}, 50 \mu \mathrm{g}$ ampicillin $\mathrm{ml}^{-1}$. The loss of the $s a c B$ gene by a second crossover allows the host to grow on medium supplemented with $5 \%$ sucrose. Thus to select for a double crossover event we plated all PAO1 transconjugants that were gentamicin resistant on LB supplemented with $5 \%$ sucrose. All gentamicin- and sucrose-resistant colonies were considered as candidates to possibly contain the double crossover. Cells were subsequently screened by PCR using primers PK4499CKF and PK4499CKR (Table 2). The confirmed disruptants with the double crossover were named PApsdR.

Complementation of the psdR mutant strain. For the complementation of the strain carrying the mutation in $p s d R$, primers PKCOMP99F and PKCOMP99R were designed, which would amplify the entire $p s d R$ gene and its promoter region. This fragment was cloned into the TOPO cloning vector. This was then digested back out from the TOPO vector using the restriction enzymes HindIII and $X b a I$. Plasmid pBBR1MCS was also digested using HindIII and XbaI. Both insert and linearized pBBRIMCS backbone were ligated at $16{ }^{\circ} \mathrm{C}$. The ligated construct, pBBR $p s d R$, was electroporated initially into E. coli and following this into the $p s d R$ mutant strain of $P$. aeruginosa. The PApsdR/pBBRpsdR strain was selected for on $50 \mu \mathrm{g}$ gentamicin $\mathrm{ml}^{-1}, 200 \mu \mathrm{g}$ chloramphenicol $\mathrm{ml}^{-1}$.

Construction of the transcriptional fusions. To characterize the transcriptional activity of the $p s d R, m d p A$ and $d p p A 3$ genes, we used the pMP220 vector bearing a promoterless lac $Z$ reporter gene. Two pairs of primers, PKTF4499F/PKTF4499R and PKTF4498F/ PKTF4498R (Table 2), were used to amplify a $592 \mathrm{bp}$ fragment containing the $p s d R-m d p A$ intergenic region with the $p s d R$ and $m d p A$ predicted promoters and part of the ORF of both genes. To facilitate directional cloning into pMP220 and a correct fusion of $p s d R$ and $m d p A$ promoters with the lac $Z$ reporter gene we introduced a PstI site downstream and an EcoRI site upstream of each promoter. Therefore, both transcriptional fusions, pTF99 ( $p s d R)$ and pTF98 $(m p d A)$, contain the full-length $m d p A-p s d R$ intergenic region but in different orientation. The two constructs were transferred into $P$. aeruginosa $\mathrm{PAO} 1$ and the PApsdR mutant strain by electroporation to produce pMP220::P $p s d R$ and pMP220::P $m d p A$ respectively. To characterize the transcriptional activity of $d p p A$ the primers PKTF4500F and PKTF4500R were used to amplify a $414 \mathrm{bp}$ region. This consisted of the entire $p s d R-d p p A$ intergenic region and the first $62 \mathrm{bp}$ of the $d p p A$ gene. To facilitate directional cloning into pMP220 and correct fusion of the $d p p A$ promoter with the lacZ reporter gene, a downstream PstI and upstream EcoRI site were introduced. This construct was then transferred into $P$. aeruginosa $\mathrm{PAO} 1$ and the $\mathrm{PA} p s d R$ mutant strain by

Table 2. Primers used in this study

\begin{tabular}{|ll|}
\hline Name & \multicolumn{1}{c|}{ Sequence $\left(\mathbf{5}^{\prime} \mathbf{3}^{\prime} \mathbf{)}\right.$} \\
\hline FRG1F & CTGCAGCGCAGATCATCGGTTCGTTGC \\
FRG1R & GCGGCCGCGCGGGGCGTCAATAAAGTCTG \\
FRG2F & GCGGCCGCGCCTACGAACGCCTGTCCAG \\
FRG2RT & CTAGAGAGATCTTCACGTCTTCGGGTTTCC \\
PK4499CKF & GTCACATTAAAATAGGGGTTCG \\
PK4499CKR & GGTCAGGACTTCCGCCACAT \\
PKCOMP99F & TCCATCATGTTCCGCAGAC \\
PKCOMP99R & TCAACGAAATTAAGCACGACT \\
PKTF4499F & GCCGCCGAATTCTACTCCCGCCAACAC \\
PKTF4499R & GCCGCCCTGCAGGGTGCAGGGTCTTCT \\
PKTF4498F & GCCGCCCTGCAGTACTCCCGCCAACAC \\
PKTF4498R & GCCGCCGAATTCGGTGCAGGGTCTTCT \\
PKTF4500F & GGCAGCGATGTGGCGGAAGTC \\
PKTF4500R & TTGCTGGCGGCGTGGGAGAAC \\
& \\
\hline
\end{tabular}


electroporation to produce PAO1/pMP220::PdppA and PApsdR/ pMP220 : : $\mathrm{P} d p p A$ respectively.

To verify the transcriptional fusion analysis the strains PApsdR/ pMP220::PdppA and PApsdR/pMP220::P $m d p A$ were complemented using the vector $p B B R p s d R$. The construct was transferred into PApsdR/pMP220:: PdppA and PApsdR/pMP220:: P $m d p A$ by electroporation to produce $\mathrm{PA} p s d R / \mathrm{pMP} 220:: \mathrm{P} d p p A$ pBBR $p s d R$ and $\mathrm{PA} p s d R / \mathrm{pMP} 220:: \mathrm{P} m d p A$ pBBR $p s d R$ respectively.

\section{Proteomic analysis}

Protein isolation. Cells were inoculated at an $\mathrm{OD}_{600}$ of 0.01 and grown to an $\mathrm{OD}_{600}$ of 0.6 in $200 \mathrm{ml}$ CAA medium. Total protein from the bacterial suspension was isolated by removing whole cells from the culture by centrifugation (7000 r.p.m., $10 \mathrm{~min}$ at $4{ }^{\circ} \mathrm{C}$ ) using a Sorvall SS-34 rotor in a Sorvall RC-5B centrifuge. The pellet was resuspended in $6 \mathrm{ml}$ HEPES buffer $(0.1 \mathrm{M}, \mathrm{pH} 7.4)$, protease inhibitor cocktail, DNase (50 U), RNase $(10 \mathrm{mg})$ and $200 \mu \mathrm{MgCl}_{2}$ $(100 \mathrm{mM})$. Resuspended cells were lysed by sonication $(5 \times 20 \mathrm{~s})$. Cellular debris was removed by centrifugation (6000 r.p.m., $10 \mathrm{~min}$ at $4{ }^{\circ} \mathrm{C}$ ). Aliquots of $1-2 \mathrm{ml}$ of extracts were extracted twice with $1 \mathrm{ml}$ phenol heated for $10 \mathrm{~min}$ at $70{ }^{\circ} \mathrm{C}$. The proteins (solid phase) were precipitated by adding $2 \mathrm{ml}$ acetone.

Two-dimensional gel electrophoresis. Pellets were resolubilized in solution A [7 M urea, $2 \mathrm{M}$ thiourea, $4 \%$ (w/v) CHAPS, and $50 \mathrm{mM}$ DTT] and diluted to a concentration of $10 \mathrm{mg}$ protein $\mathrm{ml}^{-1}$. Then $100 \mu \mathrm{l}$ solution B [7 M urea, $2 \mathrm{M}$ thiourea, 4\% (w/v) CHAPS, $50 \mathrm{mM}$ DTT, carrier ampholytes, Triton X-100 and bromophenol blue $\left(0.005 \mathrm{~g} \mathrm{ml}^{-1}\right)$ ] were added to $3 \mathrm{mg}$ protein. Proteins were loaded by in-gel rehydration on $24 \mathrm{~cm} \mathrm{pH} \mathrm{4-7} \mathrm{immobilized} \mathrm{pH}$ gradient (IPG) strips (Amersham Biosciences). Isoelectric focusing was conducted for a total of $89 \mathrm{kV}$ h. IPG strips were then reduced, alkylated and loaded for second-dimension SDS-PAGE as described previously (Nouwens et al., 2000). Coomassie-blue-stained gels were imaged using a Fluor-S Multimager. To reduce the likelihood of false variations in spot intensity, protein mix from each sample was separated in triplicate gels. The $2 \mathrm{D}$ gel electrophoresis was repeated twice in two different experiments. To reduce gel-to-gel variation within the three repeated gels for each strain, one average gel for the proteome of each strain was generated using Photoretix PG200 software (Nonlinear Dynamics).

Peptide mass mapping. Protein spots were excised from the gel, washed three times with $120 \mu \mathrm{l}$ ammonium bicarbonate ( $\mathrm{pH} 7.8$, $25 \mathrm{mM}$ )/acetonitrile $50 \%(\mathrm{v} / \mathrm{v})$ and dried using a SpeedVac (Savant Instruments). Gel pieces were rehydrated with $8 \mu \mathrm{l}$ ammonium bicarbonate $(25 \mathrm{mM}, \mathrm{pH} 7.8)$ containing $10 \mathrm{ng}$ porcine modified trypsin $\mu \mathrm{l}^{-1}$ (Promega) for $10 \mathrm{~min}$ at room temperature. Proteins were then digested at $37{ }^{\circ} \mathrm{C}$ for $16 \mathrm{~h}$. Peptides were extracted from the gel in $8 \mu \mathrm{l} 50 \%$ acetonitrile/1\% trifluoroacetic acid (TFA). A $1 \mu 1$ aliquot of each extract was spotted onto a target plate, covered with $1 \mu \mathrm{l} 8 \mathrm{mg} \alpha$-cyano-4-hydroxycinnamic acid $\mathrm{ml}^{-1}$ in $50 \%$ acetonitrile/ $1 \%$ TFA and allowed to dry. Peptide masses were generated by matrix-assisted laser desorption/ionization time-of-flight mass spectrometry (MALDI-TOF MS) using a Maldi-TOF Voyager DEPro. All spectra were obtained in reflectron mode using an accelerating voltage of $20 \mathrm{kV}$. Mass calibration was performed using Calibration Mix 2 (PE Biosystems) as an external standard. The peptide mass profile was analysed using Data Explore (PerSeptive Biosystems) software and tested against the Mascot Peptide Mass Fingerprint database (http://www.matrixscience.com). The parameters for a successful identification included a mass tolerance of 150 p.p.m. per peptide and total sequence coverage greater than $30 \%$. Identified proteins were reconfirmed by checking their predicted mass and pI values against their location in the gels.
Epithelial cell infection conditions. For infection studies, cells were washed twice with phosphate-buffered saline, detached and resuspended in the described cell culture medium and seeded at the appropriate cell number 5 days prior to infection to obtain confluent monolayers on the day of infection. Bacterial strains were cultured overnight aerobically for $16-18 \mathrm{~h}$ in cell culture medium without antibiotics (infection medium) at $37^{\circ} \mathrm{C}$. Following PBS washing to remove extracellular components, bacterial densities (in infection medium) were adjusted so as to infect PBS-washed, fully confluent cell monolayers at an m.o.i. of approximately $50: 1$. Serial dilutions were plated onto LB agar to confirm both the m.o.i. used and the bacterial numbers after $9 \mathrm{~h}$ of infection. C.f.u. $\mathrm{ml}^{-1}$ values for mutant and wild-type strains showed no significant difference. Quantification of cytotoxicity was carried out for mPAO1 and the $m d p A$ mutant strain as previously described (O'Grady et al., 2006).

Growth curve analysis. Mutants and parent strains were grown overnight in M9 minimal medium (Sambrook et al., 1989) supplemented with glucose. Cells were then washed in quarterstrength Ringer's solution and resuspended at a final $\mathrm{OD}_{600}$ of 0.01 in M9 minimal medium supplemented with different dipeptides (GlyAsp, Gly-Gln, Gly-Gly, Gly-Phe, Gly-Ala, Ala-Val, Val-Val, Phe-Pro, Gly-Pro) at a concentration of $10 \mathrm{mM}$. $\mathrm{OD}_{600}$ readings were taken over a 4 day period ( $30 \mathrm{~s}$ every $15 \mathrm{~min}$ ) with cultures grown with shaking at $37^{\circ} \mathrm{C}$. Analysis of growth was carried out using the Bioscreen C (Oy Growth Curves, Helsinki, Finland) 200-well culture growth monitoring instrument.

\section{RESULTS}

\section{Bioinformatic analysis identifies novel genes associated with the $d p p$ operon}

Bioinformatic analysis of the dipeptide transport genes in all sequenced Pseudomonas strains has highlighted different levels of complexity in the operon structure (Fig. 1). In particular the cluster of genes associated with $d p p$ transport in $P$. aeruginosa strains PAO1 and PA14 contains an extra four genes which encode a putative transcriptional regulator (PsdR), a putative metallopeptidase (MdpA) and two predicted dipeptide-binding proteins (DppA1, DppA2). The $m d p A$ and $p s d R$ genes are not found in the genomes of Pseudomonas entomophila L48 (Vodovar et al., 2006), P. putida KT2440 (Nelson et al., 2002), P. syringae pv. tomato DC3000 (Buell et al., 2003), P. syringae pv. syringae B728a (Feil et al., 2005) and P. syringae pv. phaseolicola 1448A (Joardar et al., 2005). Bioinformatic analysis of $m d p A$, located upstream of the putative transcriptional regulator $p s d R$, has identified the protein as a putative metallopeptidase. BLASTP pairwise comparisons showed that MdpA has substantial amino sequence similarity to and domain conservation with Xaa-Pro aminopeptidases. Domain analysis showed that PsdR is a MerR family-like regulator with a helix-turn-helix (HTH) XRE (xenobiotic response element) domain and a cupin sensor domain. In P. fluorescens Pf-5 bioinformatic analysis identified a region with DNA sequence homology to $p s d R$. However, this DNA sequence was found to contain an internal stop codon. 


\section{P. aeruginosa PA01, PA-14}

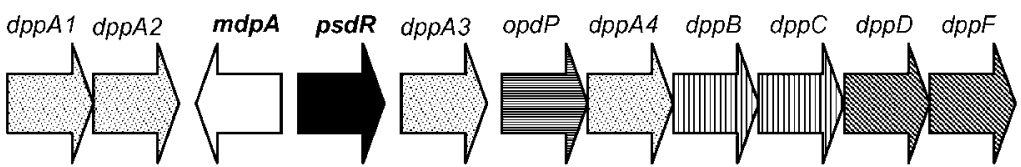

P. fluorescens Pf-5
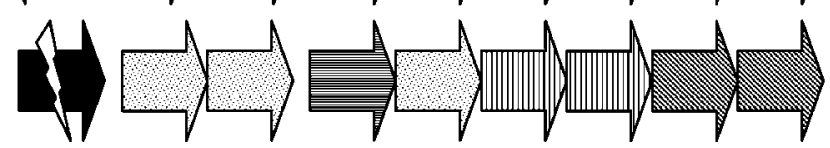

P. entomophila L48

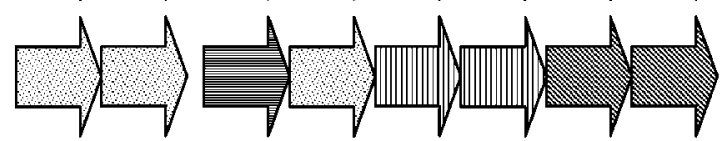

P. putida KT2440, P. syringae DC3000, b728a

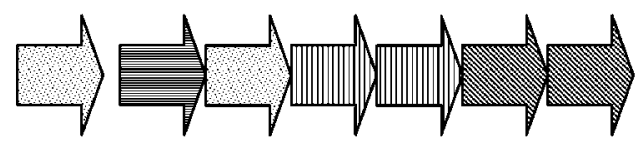

Escherichia coli $\mathrm{K} 12$

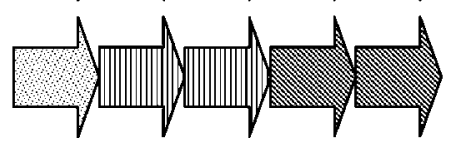

Fig. 1. Genomic organization of genes associated with $d p p$ transport in sequenced Pseudomonas species and E. coli K-12. The $d p p A 4 B C D F$ gene cluster encodes proteins involved in single and dipeptide amino acid transport (in E. coli: Abouhamad \& Manson, 1994); opdP has been shown to play a role in the transport of the dipeptide glycyl-L-glutamic acid (Tamber et al., 2006). In $P$. aeruginosa PAO1 and PA-14 the presence of genes encoding two extra putative binding proteins, $d p p A 1$, and $d p p A 2$, and the genes $m d p A$ and $p s d R$ are found. The gene $p s d R$ encodes a putative transcriptional regulator, and domain analysis has shown that PsdR belongs to the MerR family of transcriptional regulators containing a HTH XRE domain and cupin sensor residue. The gene $m d p A$ encodes a putative metallo-dipeptidase. In $P$. fluorescens Pf- 5 a region directly upstream of the $d p p$ operon is homologous to the probable transcriptional regulator, $p s d R$. This, however, is predicted to be a non-coding region because it contains an internal stop codon. The $d p p A 1,2$ and $m d p A$ genes are not present in this strain. The transport operon identified in $P$. entomophila L48 is similar to that of $P$. fluorescens and contains two additional genes encoding dipeptide-binding proteins. Other fully sequenced $P$ seudomonas species, including $P$. putida KT2440, $P$. syringae DC3000 and $P$. syringae b728a, contain the more conventional, condensed dipeptide transport operon and lack the upstream $d p p A 1,2, m d p A$ and psdR genes. The dipeptide transport operon in $E$. coli K-12 lacks a copy of the opdP gene, and contains only a single $d p p A$ gene.

\section{Proteomic analysis identifies targets of psdR}

In order to investigate the effect of the $p s d R$ gene product on the genes located immediately downstream and upstream of it, we constructed a $p s d R$ mutant (PApsdR) with a deletion covering most of the predicted promoter and half of the ORF which includes the HTH domain. Proteomic analysis was performed to examine the global impact of $p s d R$ deletion. Total proteins were extracted from PAO1 and the PApsdR mutant strains grown to an $\mathrm{OD}_{600}$ of 0.6 in CAA medium. Up to 250 protein spots were visible on gels of both mutant and wild-type strains, representing approximately $5 \%$ of the total proteome (Fig. 2). In order to reduce gel-to-gel variation within the three repeated gels for each strain, one average gel was generated for each set using Photoretix PG200 software. The use of this approach to compare proteome profiles from wild-type and the $p s d R$ mutant stain identified one genuine difference (Fig. 2a, b). The protein spot that was present in the $p s d R$ mutant and undetectable in the parent strain was characterized using MALDI-TOF MS and identified as the putative metallopeptidase, MdpA. These results suggest that the putative transcriptional regulator, PsdR, negatively regulates expression of the metallopeptidase, MdpA.

\section{PsdR negatively regulates transcription of $m d p A$ and $\mathrm{dppA3}$}

In silico analysis of the promoter region of the $m d p A$ gene was carried out to predict whether PsdR plays a direct role in regulating its expression. The promoter region identified contained a $21 \mathrm{bp}$ spacer region between the -10 and -35 consensus sites. This elongated spacer region is associated with promoters that could be under the control of MerRtype regulators (Brown et al., 2003), to which PsdR shows homology. This observation suggests that the expression of $m d p A$ could be under the control of PsdR. Inspection of the promoter region of $d p p A 3$ identified a promoter region homologous to that of $m d p A$ (Table 3 ). This suggests that PsdR may also function in regulating expression of the $d p p$ transport machinery.

Expression of $m d p A$ in a $p s d R$ mutant strain was much higher than in the wild-type based on $\beta$-galactosidase transcriptional fusion analysis. Expression was also growth phase dependent, with maximum levels seen at midexponential phase (Fig. 3a). This result indicates that expression of $m d p A$ is negatively regulated by PsdR. Expression of $d p p A 3$ was significantly higher in the mutant backround, and levels of expression increased throughout 
(a)

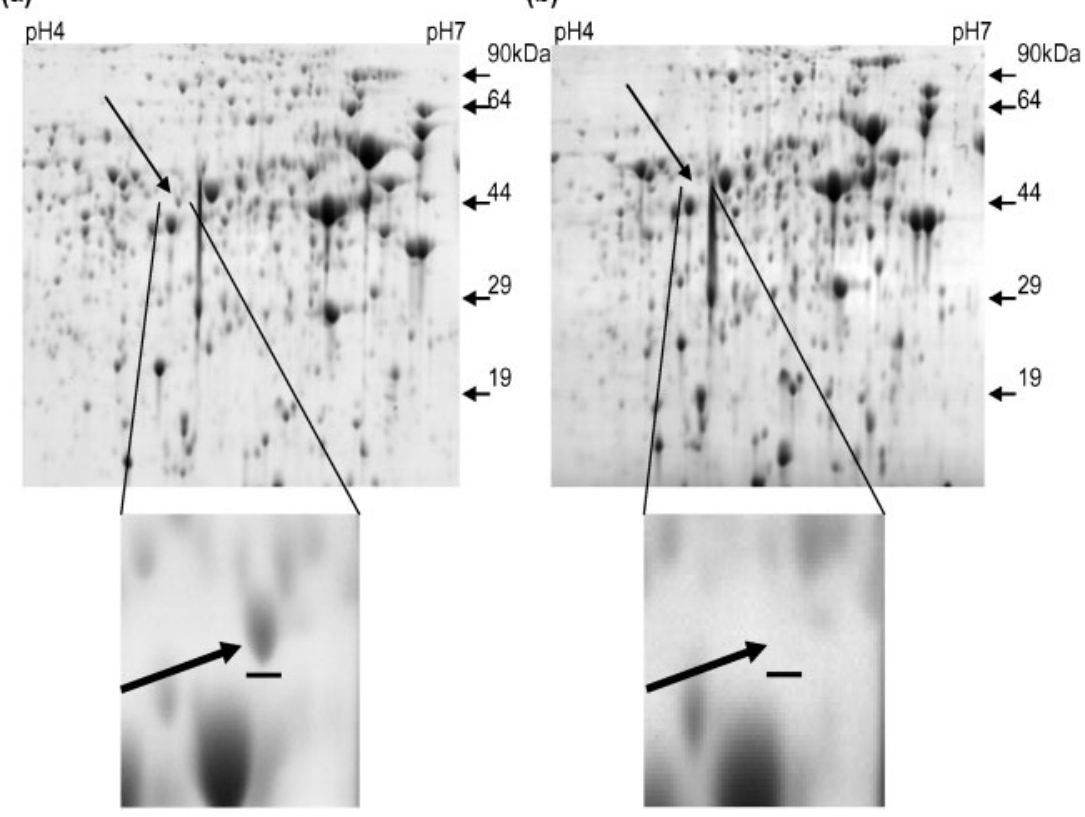

Fig. 2. Two-dimensional gel electrophoresis proteome profiles of the $p s d R$ mutant (a) and wild-type PAO1 (b) strains. The 2D analysis was carried out in two independent experiments with triplicate gels for the mutant and the wild-type. The arrows indicate the protein spot corresponding to MdpA present in the mutant and undetectable in the wild-type. Triplicate gels were analysed using Photoretix PG200 software. The protein spot was identified by MALDI-TOF. growth. This result suggested that $d p p A 3$ expression is also negatively regulated by $p s d R$. When the $p s d R$ mutant was complemented with the plasmid pBBRpsdR, the level of expression of $m d p A$ was similar to wild-type and remained below 400 Miller units over the $24 \mathrm{~h}$ period. A similar pattern emerged when expression of $d p p A$ was analysed in a $p s d R$ complemented strain, with levels of expression similar to those of the wild-type (data not shown). This verifies that a mutation in $p s d R$ results in increased expression of both $m d p A$ and $p s d R$.

\section{MdpA and PsdR are involved in the metabolism of a range of dipeptides}

The characterization of the porin OpdP and its specificity for the transport of the dipeptide glycyl-L-glutamic acid (Tamber et al., 2006) in $P$. aeruginosa $\mathrm{PAO} 1$ prompted us to hypothesize that MdpA may be involved in the metabolism of this dipeptide. This was examined by assessing the wild-type and an $m d p A$ mutant strain for growth in the presence of different dipeptide carbon sources including glycyl-L-glutamic acid. Wild-type and $m d p A$ mutant strains showed indistinguishable growth in M9 minimal medium supplemented with glucose as a carbon source (data not shown). Unlike the wild-type the $m d p A$ mutant strain was unable to utilize a range of dipeptides as a sole carbon source (Table 4). A $p s d R$ mutant strain was also compared to wild-type for growth when these dipeptides were used as sole carbon sources. Disruption of $p s d R$ resulted in a shorter lag phase of growth when these dipeptides, including Gly-Glu (Fig. 4b), were used. When X-Pro dipeptides, including Phe-Pro and Gly-Pro (Fig. 4c), were used as carbon sources, the growth kinetics of wild-type and mutant strains were more similar.

\section{The $m d p A$ gene is induced in the presence of $X$ - Pro dipeptides}

In an attempt to determine whether $m d p A$ is induced in the presence of dipeptides, its expression was analysed using a reporter strain with an $m d p A-l a c Z$ transcriptional fusion grown in M9 minimal medium supplemented with different dipeptides: Gly-Asp, Gly-Gln, Gly-Gly, Gly-Phe, Gly-Ala, Ala-Val, Val-Val, Phe-Pro, Gly-Pro. Cells were harvested at an $\mathrm{OD}_{600}$ of 0.7 , a value at which cultures had previously been shown to have the highest level of expression of $m d p A$ in M9 minimal medium (data not shown).

Table 3. Alignment of putative promoter regions of $m d p A$ and $d p p A$ genes of $P$. aeruginosa

\begin{tabular}{|c|c|c|c|}
\hline Promoter & Putative regulator & Sequence ${ }^{\star}$ & Spacer \\
\hline$m d p A$ & $p s d R$ & CATGGAAAGGCGAGAGTTGCCATGGCCCATAAGGC & $21 \mathrm{bp}$ \\
\hline \multirow[t]{2}{*}{$d p p A$} & $p s d R$ & GACTGAAAATT-TGTTTTGACCTGAAT-TTAAGCT & $19 \mathrm{bp}$ \\
\hline & & 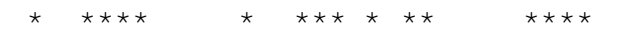 & \\
\hline
\end{tabular}

${ }^{\star}$ The -35 (left) and -10 (right) sequences are underlined. 
(a)
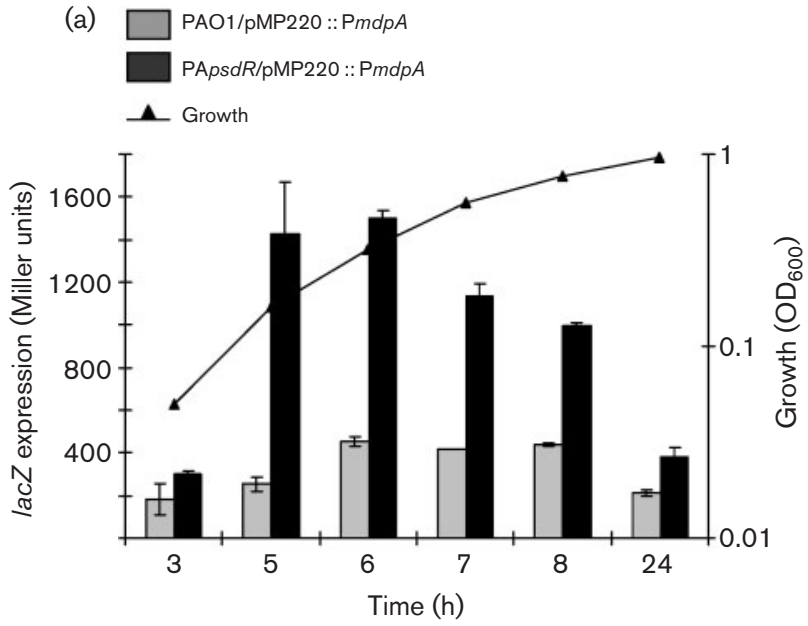

(b)

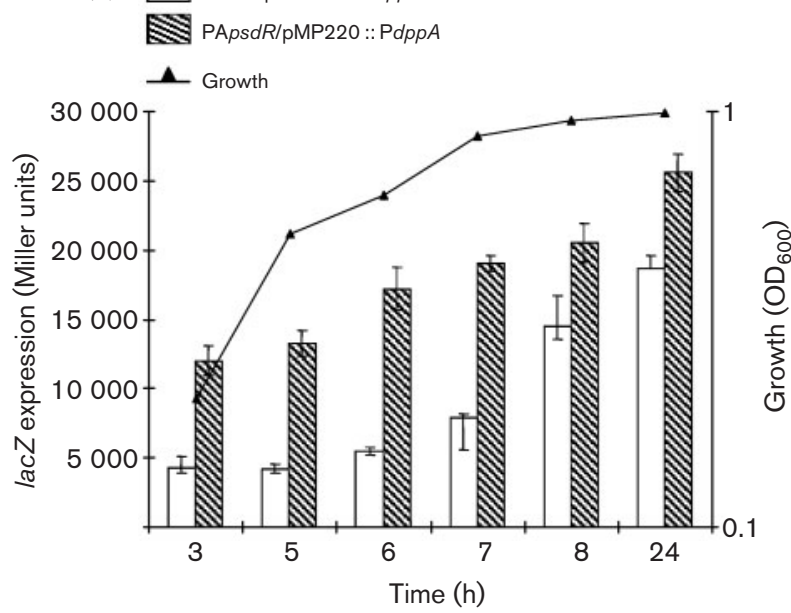

Fig. 3. Role of $P s d R$ in regulating expression of $m d p A$ and $d p p A 3$ : kinetics of expression of (a) $m d p A$ and (b) $d p p A 3$ transcriptional reporter lac $Z$ fusions in $P$. aeruginosa $\mathrm{PAO} 1$ and the $p s d R$ mutant. Cultures were grown in M9 minimal medium supplemented with glucose. Experiments were carried out in triplicate; means \pm SE are presented. (a) lacZ expression of $m d p A$ is significantly higher in the mutant strain disrupted in $p s d R$ compared to wild-type (LSD, $P=0.05$ ), and this difference is growth phase dependent. (b) Expression of $d p p A$ is also significantly higher in the mutant strain disrupted in $p s d R$ (LSD, $P=0.05$ ) but the pattern of expression as a function of growth phase is different. Complementation of $p s d R$ restores expression to wild-type levels (data not shown).
Expression of $m d p A$ was significantly induced, about fourfold, only in the presence of the X-Pro dipeptides (Phe-Pro, Gly-Pro) (Fig. 5). This result indicated that the $m d p A$ gene promoter is directly or indirectly induced by $\mathrm{X}$ Pro dipeptides.

\section{Dipeptidase MdpA plays a role in cytotoxicity of P. aeruginosa PA01}

Transcriptomic evidence shows induction of $m d p A$ in the presence of epithelial cells in the highly virulent LES isolates of P. aeruginosa (Frisk et al., 2004; Salunkhe et al., 2005). This prompted us to test the role of $m d p A$ in virulence using a cytotoxicity assay on human epithelial cells. Cytotoxicity of airway epithelial cells was measured by quantifying the release of lactate dehydrogenase into culture supernatants. At an m.o.i. of 50:1, PAO1 was about four times more cytotoxic to airway epithelial cells than the $m d p A$ mutant at $6 \mathrm{~h}$ post-infection (Fig. 6). Thus $m d p A$ appears to contribute to cytotoxicity in PAO1.

\section{DISCUSSION}

We have identified a transcriptional regulator, PsdR, and characterized its role in the regulation of the $d p p$ transport operon and dipeptide metabolism in P. aeruginosa PAO1. PsdR has a HTH domain at its N-terminal region. The HTH domain is a common DNA-binding motif found in several bacterial and eukaryotic repressors as well as activators. Domain analysis showed that PsdR is a MerRlike regulator. Deletion of most of the predicted promoter and the HTH region of PsdR led to significant increase in transcription of $m d p A$ and $d p p A 3$. It is noteworthy that the $p s d R$ mutation affects the levels and not the pattern of expression of both genes. The structure of PsdR and its effect on $m p d A$ and $d p p A 3$ expression strongly suggest that it is a repressor of the expression of these two genes and may directly interact with their promoters. At this stage it is not possible to exclude an indirect control of $m d p A$ and $d p p A 3$ transcription by PsdR. The $p s d R$ mutant strain shows a shorter lag phase of growth than the wild-type when different dipeptides are supplied as the sole carbon source. This is consistent with the observation that the mutant would have increased expression of genes responsible for both dipeptide transport and metabolism. Interestingly, the dipeptide carbon sources on which the wild-type and the $p s d R$ mutant strain have similar growth rates are the X-Pro dipeptides. These dipeptides have been

Table 4. Growth of mPAO1 and an $m d p A$ mutant strain on different dipeptides as the sole carbon source

- , No growth;,$+ \mathrm{OD}_{600} 0.1-0.3 ;++, \mathrm{OD}_{600}>0.3$.

\begin{tabular}{|lccccccc|}
\hline & Gly-Glu & Gly-Phe & Phe-Pro & Gly-Pro & Ala-Val & Gly-Ala & Gly-Asp \\
\hline mPAO1 & + & + & ++ & ++ & + & + & - \\
mPA $m d p A$ & - & - & - & - & - & - & - \\
\hline
\end{tabular}


(a) Glucose

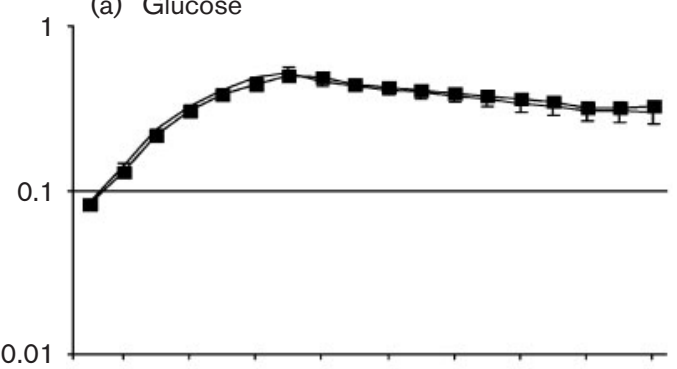

(b) Gly-Glu

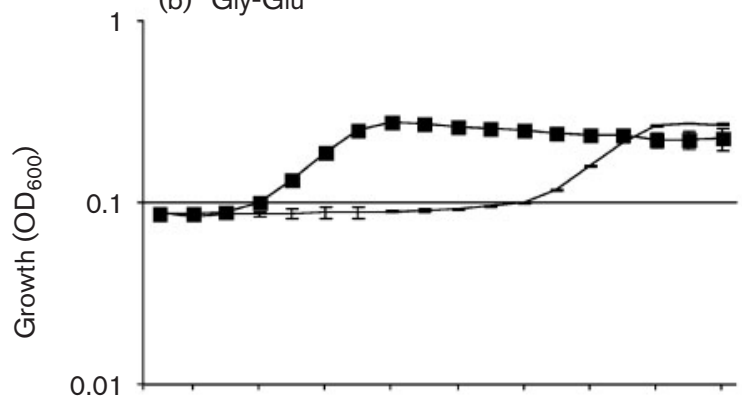

(c) Gly-Pro

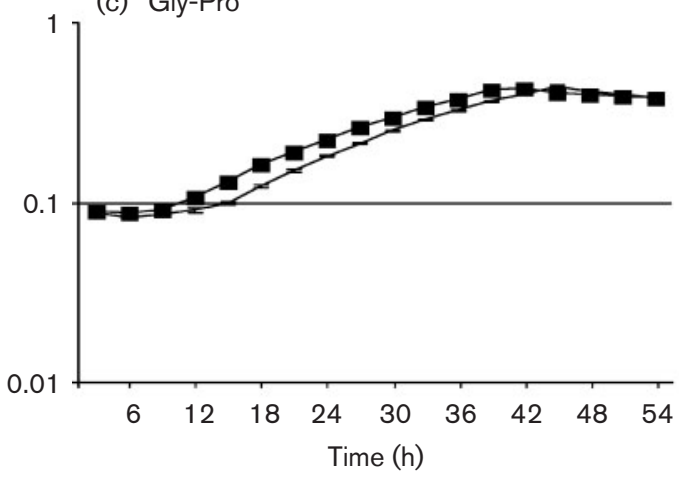

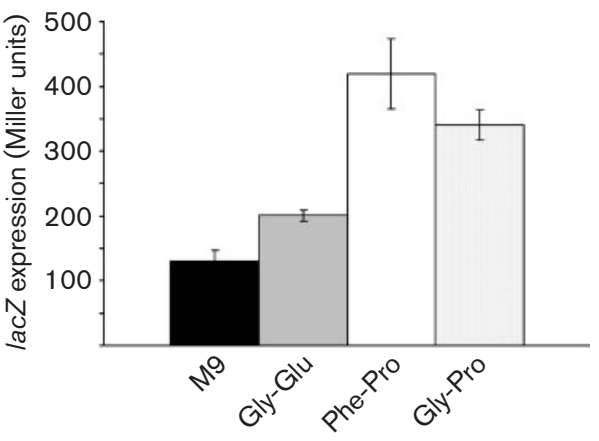

Fig. 5. Specific dipeptides induce expression of the $m d p A \beta$ galactosidase transcriptional fusion in $P$. aeruginosa PAO1. Cultures were grown in M9 minimal medium supplemented with different dipeptides and grown to an $\mathrm{OD}_{600}$ of 0.7. Experiments were carried out in triplicate; means \pm SE are presented. Expression of $m d p A$ is higher in the presence of the X-Pro (Phe-Pro, Gly-Pro) dipeptides.

dependent. This suggests that $m d p A$ is under control of other regulators which are not affected by PsdR. Previous experimental evidence suggests that the regulation of expression of $m d p A$ is complex and is controlled by many regulatory inputs. Transcriptome analysis suggests that $m d p A$ is regulated by quorum-sensing-dependent regulators LasR and RhlR in $P$. aeruginosa PAO1. Expression was shown to be ninefold higher when the PAO1 and lasR/rhlR double mutant strains were compared (Schuster et al., 2003). A similar phenotype is seen in the post-transcriptional regulator rsmA mutant background (Burrowes et al., 2006).

Transcriptome-profiling experiments had previously shown that $m d p A$ is induced both in the presence of an epithelial cell line (Frisk et al., 2004) and in a highly virulent LES isolate of P. aeruginosa PAO1 (Salunkhe et al., 2005). This result suggested to us that this gene could play a specific role in interactions with epithelial cells. Interestingly, a mutation in $m d p A$ results in reduced cytotoxicity of the bacterium to an epithelial cell line (Fig. 6). P. aeruginosa produces several proteases that are implicated in the process of infections caused by this organism (Doring et al., 1985). Most clinical strains of $P$. aeruginosa produce elastase, a zinc metalloprotease that is implicated in the pathogenesis of infections related to these organisms. Indeed, numerous other examples of proteases and aminopeptidases that are linked to virulence have been highlighted (Coffey et al., 2000; Corbett et al., 2003; Feil et al., 2005; Hidalgo-Grass et al., 2006; Kooi et al., 2006; Song et al., 2004; Spratt et al., 1995). Dipeptidyl aminopeptidase activity has previously been implicated in the virulence of Porphyromonas gingivalis (Kumagai et al., 2000). This aminopeptidase has been shown to function extracellularly. However, sequence analysis of MdpA does not show the presence of a signal peptide involved in triggering protein translocation; it rather suggests a cytoplasmic location for this protein. The exact mechanism of how the dipeptidase MdpA is involved in virulence is unknown. 


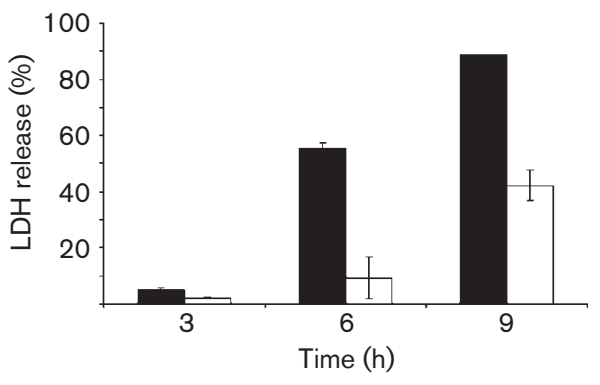

Fig. 6. Analysis of cytotoxicity of $P$. aeruginosa strains mPAO1 (black bars) and mPAmdpA (white bars). Cytotoxicity was determined in triplicate experiments by quantifying the release of lactate dehydrogenase (LDH) into culture supernatants. Means \pm SE are presented. Strain $m P A m d p A$ had reduced cytotoxicity compared to the wild-type.

Analysis of Pseudomonas genomes has shown the presence of the $m d p A$ dipeptidase gene specifically in $P$. aeruginosa strains and not in other sequenced Pseudomonas species. Questions remain regarding what biological roles both the regulator and peptidase play in Pseudomonas-host interactions. The contribution of MdpA is potentially explained by its role in cytotoxicity, presumably because of the advantages in nutrient metabolism it affords. The physiological role of PsdR, which functions as a repressor of both dipeptide transport and metabolism, is less clear. Perhaps a tighter regulation of genes involved in the uptake and metabolism of small molecules into the cell is required for the successful colonization of environments in which $P$. aeruginosa is prominent.

It is assumed that the genetic complexity of $P$. aeruginosa allows for its ecological and metabolic versatility. Analysis of the $d p p$ gene cluster in $P$. aeruginosa, the characterization of novel genes associated with both nutrient transport and metabolism and the role of $m d p A$ in cytotoxicity would support this view.

\section{ACKNOWLEDGEMENTS}

We acknowledge Joanne Cummins, Simon Miller, Claire Adams and Pat Higgins for useful advice and discussions. This research was supported in part by grants awarded by the European Commission (MTKD-CT-2006-042062; O36314), the Science Foundation of Ireland (SFI 02/IN.1/B1261; 04/BR/B0597), the Department of Agriculture and Food (DAF RSF 06 321; DAF RSF 06 377), Irish Research Council for Science, Engineering and Technology (IRCSET) (05/EDIV/FP107;), the Health Research Board (RP/2004/145; RP/2006/271; RP/2007/290), the Environmental Protection Agency (EPA 2006-PhD-S-21) and the Higher Education Authority of Ireland (PRTLI3).

\section{REFERENCES}

Abouhamad, W. N. \& Manson, M. D. (1994). The dipeptide permease of Escherichia coli closely resembles other bacterial transport systems and shows growth-phase-dependent expression. Mol Microbiol 14, 1077-1092.
Abouhamad, W. N., Manson, M., Gibson, M. M. \& Higgins, C. F. (1991). Peptide transport and chemotaxis in Escherichia coli and Salmonella typhimurium: characterization of the dipeptide permease (Dpp) and the dipeptide-binding protein. Mol Microbiol 5, 1035-1047.

Altschul, S. F., Gish, W., Miller, W., Myers, E. W. \& Lipman, D. J. (1990). Basic local alignment search tool. J Mol Biol 215, 403-410.

Brown, N. L., Stoyanov, J. V., Kidd, S. P. \& Hobman, J. L. (2003). The MerR family of transcriptional regulators. FEMS Microbiol Rev 27, 145-163.

Buell, C. R., Joardar, V., Lindeberg, M., Selengut, J., Paulsen, I. T., Gwinn, M. L., Dodson, R. J., Deboy, R. T., Durkin, A. S. \& other authors (2003). The complete genome sequence of the Arabidopsis and tomato pathogen Pseudomonas syringae pv. tomato DC3000. Proc Natl Acad Sci U S A 100, 10181-10186.

Burrowes, E., Baysse, C., Adams, C. \& O'Gara, F. (2006). Influence of the regulatory protein RsmA on cellular functions in Pseudomonas aeruginosa $\mathrm{PAO} 1$, as revealed by transcriptome analysis. Microbiology 152, 405-418.

Carter, R. A., Yeoman, K. H., Klein, A., Hosie, A. H., Sawers, G., Poole, P. S. \& Johnston, A. W. (2002). dpp genes of Rhizobium leguminosarum specify uptake of $\delta$-aminolevulinic acid. Mol Plant Microbe Interact 15, 69-74.

Chenna, R., Sugawara, H., Koike, T., Lopez, R., Gibson, T. J., Higgins, D. G. \& Thompson, J. D. (2003). Multiple sequence alignment with the CLUSTAL series of programs. Nucleic Acids Res 31, 3497-3500.

Coffey, A., van den Burg, B., Veltman, R. \& Abee, T. (2000). Characteristics of the biologically active $35-\mathrm{kDa}$ metalloprotease virulence factor from Listeria monocytogenes. J Appl Microbiol 88, 132141.

Corbett, C. R., Burtnick, M. N., Kooi, C., Woods, D. E. \& Sokol, P. A. (2003). An extracellular zinc metalloprotease gene of Burkholderia cepacia. Microbiology 149, 2263-2271.

Doring, G., Goldstein, W., Roll, A., Schiotz, P. O., Hoiby, N. \& Botzenhart, K. (1985). Role of Pseudomonas aeruginosa exoenzymes in lung infections of patients with cystic fibrosis. Infect Immun 49, $557-562$.

Feil, H., Feil, W. S., Chain, P., Larimer, F., DiBartolo, G., Copeland, A., Lykidis, A., Trong, S., Nolan, M. \& other authors (2005). Comparison of the complete genome sequences of Pseudomonas syringae pv. syringae B728a and pv. tomato DC3000. Proc Natl Acad Sci U S A 102, 11064-11069.

Figurski, D. H. \& Helinski, D. R. (1979). Replication of an origincontaining derivative of plasmid RK2 dependent on a plasmid function provided in trans. Proc Natl Acad Sci U S A 76, 16481652.

Frisk, A., Schurr, J. R., Wang, G., Bertucci, D. C., Marrero, L., Hwang, S. H., Hassett, D. J. \& Schurr, M. J. (2004). Transcriptome analysis of Pseudomonas aeruginosa after interaction with human airway epithelial cells. Infect Immun 72, 5433-5438.

Govan, J. R. \& Deretic, V. (1996). Microbial pathogenesis in cystic fibrosis: mucoid Pseudomonas aeruginosa and Burkholderia cepacia. Microbiol Rev 60, 539-574.

Guedon, E., Serror, P., Ehrlich, S. D., Renault, P. \& Delorme, C. (2001). Pleiotropic transcriptional repressor CodY senses the intracellular pool of branched-chain amino acids in Lactococcus lactis. Mol Microbiol 40, 1227-1239.

Hidalgo-Grass, C., Mishalian, I., Dan-Goor, M., Belotserkovsky, I., Eran, Y., Nizet, V., Peled, A. \& Hanski, E. (2006). A streptococcal protease that degrades CXC chemokines and impairs bacterial clearance from infected tissues. EMBO J 25, 4628-4637. 
Holloway, B. W. \& Morgan, A. F. (1986). Genome organization in Pseudomonas. Annu Rev Microbiol 40, 79-105.

Jacobs, M. A., Alwood, A., Thaipisuttikul, I., Spencer, D., Haugen, E., Ernst, S., Will, O., Kaul, R., Raymond, C. \& other authors (2003). Comprehensive transposon mutant library of Pseudomonas aeruginosa. Proc Natl Acad Sci U S A 100, 14339-14344.

Jander, G., Rahme, L. G. \& Ausubel, F. M. (2000). Positive correlation between virulence of Pseudomonas aeruginosa mutants in mice and insects. J Bacteriol 182, 3843-3845.

Joardar, V., Lindeberg, M., Jackson, R. W., Selengut, J., Dodson, R., Brinkac, L. M., Daugherty, S. C., Deboy, R., Durkin, A. S. \& other authors (2005). Whole-genome sequence analysis of Pseudomonas syringae pv. phaseolicola 1448A reveals divergence among pathovars in genes involved in virulence and transposition. J Bacteriol 187, $6488-6498$.

King, N. D. \& O'Brian, M. R. (1997). Identification of the $\operatorname{lrp}$ gene in Bradyrhizobium japonicum and its role in regulation of $\delta$-aminolevulinic acid uptake. J Bacteriol 179, 1828-1831.

Kooi, C., Subsin, B., Chen, R., Pohorelic, B. \& Sokol, P. A. (2006). Burkholderia cenocepacia $\mathrm{ZmpB}$ is a broad-specificity zinc metalloprotease involved in virulence. Infect Immun 74, 4083-4093.

Kovach, M. E., Phillips, R. W., Elzer, P. H., Roop, R. M., II \& Peterson, K. M. (1994). pBBR1MCS: a broad-host-range cloning vector. Biotechniques 16, 800-802.

Kube, D., Sontich, U., Fletcher, D. \& Davis, P. B. (2001). Proinflammatory cytokine responses to $P$. aeruginosa infection in human airway epithelial cell lines. Am J Physiol Lung Cell Mol Physiol 280, L493-L502.

Kumagai, Y., Konishi, K., Gomi, T., Yagishita, H., Yajima, A. \& Yoshikawa, M. (2000). Enzymatic properties of dipeptidyl aminopeptidase IV produced by the periodontal pathogen Porphyromonas gingivalis and its participation in virulence. Infect Immun 68, 716-724.

Letoffe, S., Delepelaire, P. \& Wandersman, C. (2006). The housekeeping dipeptide permease is the Escherichia coli heme transporter and functions with two optional peptide binding proteins. Proc Natl Acad Sci U S A 103, 12891-12896.

Nelson, K. E., Weinel, C., Paulsen, I. T., Dodson, R. J., Hilbert, H., Martins dos Santos, V. A., Fouts, D. E., Gill, S. R., Pop, M. \& other authors (2002). Complete genome sequence and comparative analysis of the metabolically versatile Pseudomonas putida KT2440. Environ Microbiol 4, 799-808.

Nouwens, A. S., Cordwell, S. J., Larsen, M. R., Molloy, M. P., Gillings, M., Willcox, M. D. \& Walsh, B. J. (2000). Complementing genomics with proteomics: the membrane subproteome of Pseudomonas aeruginosa PAO1. Electrophoresis 21, 3797-3809.

O'Grady, E. P., Mulcahy, H., O'Callaghan, J., Adams, C. \& O'Gara, F. (2006). Pseudomonas aeruginosa infection of airway epithelial cells modulates expression of Kruppel-like factors 2 and 6 via RsmAmediated regulation of type III exoenzymes S and Y. Infect Immun 74, 5893-5902.

Ochsner, U. A., Wilderman, P. J., Vasil, A. I. \& Vasil, M. L. (2002). GeneChip expression analysis of the iron starvation response in Pseudomonas aeruginosa: identification of novel pyoverdine biosynthesis genes. Mol Microbiol 45, 1277-1287.

Pearson, W. R. \& Lipman, D. J. (1988). Improved tools for biological sequence comparison. Proc Natl Acad Sci U S A 85, 2444-2448.

Rahme, L. G., Stevens, E. J., Wolfort, S. F., Shao, J., Tompkins, R. G. \& Ausubel, F. M. (1995). Common virulence factors for bacterial pathogenicity in plants and animals. Science 268, 1899-1902.

Rajan, S., Cacalano, G., Bryan, R., Ratner, A. J., Sontich, C. U., van Heerckeren, A., Davis, P. \& Prince, A. (2000). Pseudomonas aeruginosa induction of apoptosis in respiratory epithelial cells: analysis of the effects of cystic fibrosis transmembrane conductance regulator dysfunction and bacterial virulence factors. Am J Respir Cell Mol Biol 23, 304-312.

Salunkhe, P., Smart, C. H., Morgan, J. A., Panagea, S., Walshaw, M. J., Hart, C. A., Geffers, R., Tummler, B. \& Winstanley, C. (2005). A cystic fibrosis epidemic strain of Pseudomonas aeruginosa displays enhanced virulence and antimicrobial resistance. J Bacteriol 187, 4908-4920.

Sambrook, J., Fritsch, E. F. \& Maniatis, T. (1989). Molecular Cloning: a Laboratory Manual. Cold Spring Harbor, NY: Cold Spring Harbor Laboratory.

Schafer, A., Tauch, A., Jager, W., Kalinowski, J., Thierbach, G. \& Puhler, A. (1994). Small mobilizable multi-purpose cloning vectors derived from the Escherichia coli plasmids pK18 and pK19: selection of defined deletions in the chromosome of Corynebacterium glutamicum. Gene 145, 69-73.

Schuster, M., Lostroh, C. P., Ogi, T. \& Greenberg, E. P. (2003). Identification, timing, and signal specificity of Pseudomonas aeruginosa quorum-controlled genes: a transcriptome analysis. J Bacteriol 185, 2066-2079.

Silo-Suh, L., Suh, S. J., Sokol, P. A. \& Ohman, D. E. (2002). A simple alfalfa seedling infection model for Pseudomonas aeruginosa strains associated with cystic fibrosis shows AlgT (sigma-22) and RhlR contribute to pathogenesis. Proc Natl Acad Sci U S A 99, 15699-15704.

Slack, F. J., Serror, P., Joyce, E. \& Sonenshein, A. L. (1995). A gene required for nutritional repression of the Bacillus subtilis dipeptide permease operon. Mol Microbiol 15, 689-702.

Song, T., Toma, C., Nakasone, N. \& Iwanaga, M. (2004). Aerolysin is activated by metalloprotease in Aeromonas veronii biovar sobria. $J$ Med Microbiol 53, 477-482.

Spaink, H. P., Okker, R. J. H. O., Wijffelman, C. A., Pees, E. \& Lugtenberg, B. J. J. (1987). Promoters in the nodulation region of the Rhizobium leguminosarum Sym plasmid pRL1J1. Plant Mol Biol 9, 27-39.

Spratt, D. A., Greenman, J. \& Schaffer, A. G. (1995). Capnocytophaga gingivalis aminopeptidase: a potential virulence factor. Microbiology 141, 3087-3093.

Stover, C. K., Pham, X. Q., Erwin, A. L., Mizoguchi, S. D., Warrener, P., Hickey, M. J., Brinkman, F. S., Hufnagle, W. O., Kowalik, D. J. \& other authors (2000). Complete genome sequence of Pseudomonas aeruginosa PAO1, an opportunistic pathogen. Nature 406, 959-964.

Tamber, S. \& Hancock, R. E. (2006). Involvement of two related porins, OprD and OpdP, in the uptake of arginine by Pseudomonas aeruginosa. FEMS Microbiol Lett 260, 23-29.

Tamber, S., Ochs, M. M. \& Hancock, R. E. (2006). Role of the novel OprD family of porins in nutrient uptake in Pseudomonas aeruginosa. J Bacteriol 188, 45-54.

Urbanowski, M. L., Stauffer, L. T. \& Stauffer, G. V. (2000). The gcvB gene encodes a small untranslated RNA involved in expression of the dipeptide and oligopeptide transport systems in Escherichia coli. Mol Microbiol 37, 856-868.

Vodovar, N., Vallenet, D., Cruveiller, S., Rouy, Z., Barbe, V., Acosta, C., Cattolico, L., Jubin, C., Lajus, A. \& other authors (2006). Complete genome sequence of the entomopathogenic and metabolically versatile soil bacterium Pseudomonas entomophila. Nat Biotechnol 24, 673-679.

Walker, T. S., Bais, H. P., Deziel, E., Schweizer, H. P., Rahme, L. G., Fall, R. \& Vivanco, J. M. (2004). Pseudomonas aeruginosa-plant root interactions. Pathogenicity, biofilm formation, and root exudation. Plant Physiol 134, 320-331.

Edited by: M. A. Curtis 